\title{
Selected Manufacturer's Professional Trumpet Component Specifications: A Compendium of Measurements, Materials, and Playing Characteristics
}

\author{
Kenneth H. Piatt
}

Follow this and additional works at: https://researchrepository.wvu.edu/etd

\footnotetext{
Recommended Citation

Piatt, Kenneth H., "Selected Manufacturer's Professional Trumpet Component Specifications: A Compendium of Measurements, Materials, and Playing Characteristics" (2017). Graduate Theses, Dissertations, and Problem Reports. 6416.

https://researchrepository.wvu.edu/etd/6416

This Dissertation is protected by copyright and/or related rights. It has been brought to you by the The Research Repository @ WVU with permission from the rights-holder(s). You are free to use this Dissertation in any way that is permitted by the copyright and related rights legislation that applies to your use. For other uses you must obtain permission from the rights-holder(s) directly, unless additional rights are indicated by a Creative Commons license in the record and/ or on the work itself. This Dissertation has been accepted for inclusion in WVU Graduate Theses, Dissertations, and Problem Reports collection by an authorized administrator of The Research Repository @ WVU. For more information, please contact researchrepository@mail.wvu.edu.
} 


\title{
Selected Manufacturer's Professional Trumpet Component Specifications: A Compendium of Measurements, Materials, and Playing Characteristics.
}

\author{
Kenneth H. Piatt \\ Research Project Submitted \\ to the College of Creative Arts \\ at West Virginia University \\ in partial fulfillment of the requirements for the degree of \\ Doctor of Musical Arts in \\ Music Performance
}

John Winkler, DMus, Chair

Evan MacCarthy, Ph.D., Research Advisor

Mitchell Arnold, DMA

Keith Jackson, DMA

Beth Royall, MM, MLIS

School of Music

Morgantown, West Virginia

2017

Keywords: Trumpet, Components, Measurements, Playing, Characteristics, Manufacturers, Bach, Getzen, B\&S, Schilke, Yamaha, Edwards, Leadpipes, Bells, Bore Sizes, Models 


\title{
ABSTRACT \\ Selected Manufacturer's Professional Trumpet Component Specifications: A Compendium of Measurements, Materials, and Playing Characteristics.
}

\author{
Kenneth H. Piatt
}

This compendium gathers existing information about major "mass-production" instruments in one single volume of data; a body of information not presently collected in the trumpet community. Additionally, this project aims to describe instruments using consistent terminology across instrument brands for efficient cross-referencing, comparison, and research.

Using a collection of pamphlets, catalogues, promotional literature, and website information from manufacturers, this document compiles physical instrument specifications and their playing characteristics. Specifications included are leadpipe measurements and bell mandrel profile descriptions (where available), bore sizes, metals and materials used, and general playing characteristics of each model. Manufacturers included in this document are Bach, B\&S, Getzen, Schilke, and Yamaha. These manufacturers were chosen as a representative sampling of massproduced piston trumpets commonly used in the United States 


\section{Table of Contents}

Introduction

Glossary of Terms

Describing Sound

Blow Resistance

Chapter 1: Vincent Bach Corporation $\quad 5$

Bore Sizes $\quad 5$

Bells

Bell Mandrel Numbers and Descriptions $\quad 8$

$\begin{array}{ll}\text { Leadpipes } & 10\end{array}$

Common Stradivarius Models 13

$\begin{array}{ll}\text { Artisan Collection } & 14\end{array}$

Chapter 2: The B\&S Brand 17

Bb Trumpets 17

C Trumpets 19

Eb/E/D Trumpets 20

Piccolo Trumpets 20

Chapter 3: The Getzen Company 21

Valves $\quad 21$

Bells 21

$\begin{array}{ll}\text { Artist Models } & 22\end{array}$

Chapter 4: Edwards Instrument Company 26

Bells $\quad 26$

Tuning Slides $\quad 28$

Leadpipes $\quad 29$

Models (Templates) 30

Chapter 5: Schilke Music Products 32

Bore Sizes $\quad 32$

Bells $\quad 32$

Original Designs $\quad 35$

HD Series $\quad 37$

Handcraft Series $\quad 38$

Eb and Piccolo Trumpets 38

Chapter 6: Yamaha Corporation $\quad 40$

6000 Series 40

8000 Xeno Series 41

Artist Model 9000 Series 43

$\begin{array}{ll}\text { Chapter 7: Categories of Models } & 47\end{array}$

$\begin{array}{ll}\text { Bibliography } & 50\end{array}$ 


\section{Introduction}

This compendium gathers existing information about major "mass-production" instruments in one single volume of data; a body of information not presently collected in the trumpet community. Additionally, this project aims to describe instruments using consistent terminology across instrument brands for efficient cross-referencing, comparison, and research. Using a collection of pamphlets, catalogues, promotional literature, and website information from manufacturers, this document compiles physical instrument specifications and their playing characteristics. The descriptions of playing characteristics are a collection of manufacturer descriptions, personal experience as a professional trumpet player and repair technician, and other input from various informal sources such as trumpet forums and Bach and Schilke Loyalist websites. Specifications included are leadpipe measurements and bell mandrel profile descriptions (where available), bore sizes, metals and materials used, and general playing characteristics of each model. Citations in each section are where measurements, materials, and other technical information are derived, and playing characteristics of the individual models and components are created using this information.

Manufacturers included in this document are Bach, B\&S, Getzen/Edwards, Schilke, and Yamaha. These manufacturers were chosen as a representative sampling of mass-produced piston trumpets commonly used in the United States. Bach is included first in this document, not only because of alphabetical categorization, but because the Bach brand's professional line of trumpets, the Stradivarius, has become so ubiquitous in the trumpet community that its design elements, sound characteristics, and product and component nomenclature serve as the template for most companies producing instruments today. The language and labeling used in the Bach chapter of this paper serve to guide evaluation of the other four companies' trumpets. Most of these five instrument manufacturers offer full lineups of student through professional $\mathrm{Bb}, \mathrm{C}, \mathrm{D}$, $\mathrm{Eb}, \mathrm{F}, \mathrm{G}$, piccolo, as well as rotary trumpets, flugelhorns, and cornets. This document will focus strictly on current production professional or artist level $\mathrm{Bb}, \mathrm{C}, \mathrm{D}, \mathrm{Eb}$, and piccolo trumpets. 


\section{Glossary}

Balusters: Balusters refer to the top section of the valve casing from where the top caps screw in to where the valve guides lock.

Bell Bead: At the very end of a brass instrument's bell, the metal is folded or shaped back around itself, effectively sealing the end of the sheet metal. Modern instruments have a round or flat wire soldered inside the bead.

Bell Profile: Also bell taper, this describes the literal "profile" of the bell, or shape of the flare. Bell Tail: The section of the bell exiting the first valve casing.

Bell Taper: Generally, a bell will have a fast or slow taper. A fast taper means the bell increases diameter quickly along its length, whereas a slow taper means the bell increases diameter more gradually to the end. Fast tapers will have a darker, less direct sound, and bells with slow tapers are more brilliant and cut through an ensemble more efficiently.

Crook: The crook can describe the bend of the tuning slide or bend of the bell.

Ferrule: Any tube connecting two sections of pipe; also referred to as a sleeve.

Flare: The bell flare can describe both how quickly a bell tapers and the rim, or end, of the bell.

Leadpipe: The leadpipe is the length of tubing from where the mouthpiece is placed to where the tube enters either the tuning slide or valve section.

Long-Bell: A long-bell design refers to higher keyed trumpets where the leadpipe enters into the valve block directly, and the bell has a less aggressive, 90 degree bend coming out of the valve section.

Mandrel: The steel form on which a trumpet's bell or leadpipe is shaped.

Mandrel Number: The labeling of mandrels differentiating the different bell shapes.

Receiver: Also "mouthpiece receiver," the small length of pipe where the mouthpiece is placed. A trumpet can have a receiver that fits either a cornet or trumpet mouthpiece.

Rim: The rim is the end of a bell where the bead is located.

Shank: Also the receiver, a leadpipe will have a shank that fits a cornet or trumpet mouthpiece. Short-Bell: A short-bell design refers to higher keyed trumpets with a leadpipe that curves 180 degrees going into the valve section, and a bell with a 180 degree bend coming out of the valve section 
Slotting: Brass instruments have "slots" that refer to where the partials of the instrument lock in. A trumpet can have slots that are small or wide, slippery or rigid, that describe how the instrument plays.

Solder: Solder is a lead alloy used to attach components of wind instruments. It is also used to describe the technique of applying the solder.

Throat: The throat of a bell describes either the diameter of the bell tail, or more commonly where the bell starts to flare out by the valve section.

Venturi: The opening diameter measurement of a leadpipe.

Wrap: Describes how the trumpet is "wrapped," or the distance top to bottom of the tuning slide.

For additional information regarding terms in this glossary and further research, readers may find the following of interest:

Elisa Koehler, A Dictionary for the Modern Trumpet Player (Scarecrow Press, 2015). https://books.google.com/books/about/A_Dictionary_for_the_Modern_Trumpet_Play.html?id=F fzbBgAAQBAJ.

Jeffrey Nussbaum, "A Survey of Trumpet Makers World-Wide," Historic Brass Society newsletter 14 (2001): 12-19. 


\section{Describing Sound}

Attempting to translate the sound of a trumpet to words is incredibly difficult and imprecise. Every attempt has been made to describe a trumpet's sound quality as objectively as possible using the contemporary parlance of practitioners, and the perceptions here are one person's educated opinion. Invariably, every person will hear something differently than another. In general sound is described as bright or dark, with shadings of those descriptions. A bright sound will have many upper overtones present, and if a sound is too bright, it can be piercing and offensive. By contrast, a dark sound will have a strong fundamental and may be "thick" sounding to some listeners. A direct sound is good for ensemble playing as it "cuts" well, or can be heard through a band or orchestra easily. If a sound is too spread or "diffuse," it does not project well or will not be present to the listener. Ideally, a trumpet will have a balance of sound quality, however in some situations a very bright or dark sound is preferable.

\section{Blow Resistance}

As with sound quality, a trumpet ideally will be easy to play but have enough resistance for efficient upper register playing and articulations. Some players prefer a trumpet that has a freer or "open" blow, and some players prefer more resistance. An instrument with a more resistant feel can aid in endurance, but will not be able to produce adequate volume in all situations, and the sound quality can spread more easily. Accuracy will be improved, but the tighter slots can make intonation more work for the player. Alternatively, if a horn is too open, a player can get tired very quickly, and due to the large feeling of the instrument, accuracy, articulation, and range can suffer. The perfect trumpet will be a balanced blow resistance for each player in each performance situation. 


\section{Chapter 1: Vincent Bach Corporation}

Vincent Bach Stradivarius trumpets have been the standard in sound and construction in professional trumpets since the 1940's. Bach trumpets can be found in virtually every professional ensemble in the United States. Because of their popularity, nearly every trumpet manufacturer selling instruments in the United States is attempting to copy or is directly influenced by the Bach sound. Bach trumpets designs have changed slightly as the company moved from New York City, Mt. Vernon, NY, and finally Elkhart IN. This section will describe current era Elkhart instruments and serve not only as a guide to Bach's trumpets, but also a reference point for the other four collections of instruments in this document.

\section{$\underline{\text { Bach Bore Sizes }}^{1}$}

Trumpet bores are measured at the point of the second valve slide in the valve casing. All trumpets flare differently from the opening venturi to the bell tail, so often times the bore is not a consistent measurement between models. Very generally, a larger bore will allow the player to put more air through the trumpet more quickly, resulting in easier production of louder volumes. All components rely on balance to achieve a desired function, so it is possible for a smaller bore to have less blow resistance than a larger bore in a different model.

XS: .401 inches - a bore found specifically on Bach's higher keyed instruments.

S: .448 inches - a rare bore only made by special request.

M: .453 inches

ML: .459 inches - the standard bore on Bach's Bb trumpets.

L: .462 inches - standard on Bach's $\mathrm{C}$ trumpets.

XL: .468 inches - rarely found, and only made by special order.

MLV: "Vindibona" bore. Rare, a fast, conical style flare from .453-.459 inches.

\footnotetext{
1 “Conn Selmer: Professional Trumpets," Conn-Selmer, Bach Brass, 2017, accessed April 5, 2017, http://www.bachbrass.com/bach/instruments/trumpets/professional.
} 


\section{$\underline{\text { Bach Stradivarius Bells }}^{2}$}

\section{Materials}

Yellow Brass: The standard material for all Bach bells. Bach's exact brass alloy is proprietary, but a typical yellow brass formula is $70 \%$ copper and 30\% zinc. This metal produces a balanced tone.

Gold Brass: This metal has a higher copper content than yellow brass, about $85 \%$ copper to $15 \%$ zinc. This metal is softer and more malleable than yellow brass, thus absorbing some of the sympathetic vibrations while playing. Higher overtones in the sound are weaker in trumpets with bells made of gold brass and are described as having a "darker" tone. Gold brass bells are marked with a "G" on the bell after the mandrel number.

Sterling Plus: A rarer option that is available on request with some bells. True sterling silver is an alloy consisting of $92.5 \%$ silver; Bach's silver alloy, "Sterling Plus," is advertised as $99.9 \%$ pure silver. These bells are electroformed on a mandrel and therefore do not have a seam like their brass bells. Pure silver is incredibly soft and structurally fragile, so considerable care must be taken with these bells to prevent damage. A trumpet with a silver bell will have a very direct sound with a strong fundamental and very present upper overtones. Projection in a large ensemble can be difficult with this bell. A "Sterling Silver Plus" stamping will be found on these bells.

\section{Bell weight ${ }^{3}$}

Standard Weight: Bach's modern standard weight sheet brass is 22 gauge, or .025 inches in thickness. This weight offers a balance of response and projection.

\footnotetext{
${ }^{2}$ Vincent Bach, Trumpet and Trombone Inventory Catalogue, (Elkhart, IN: Conn-Selmer Inc.), 18.; "Bach Trumpets - Bells," Bach Loyalist, 2006, accessed April 5, 2017, http:/www.bachloyalist.com/bach-trumpets-bells/.

3 “Bach Trumpets - Bell Variations," Bach Loyalist, 2006, accessed April 5, 2017, http://www.bachloyalist.com/bach-trumpets-bell-variations/.
} 
Lightweight: The thickness of Bach's lightweight sheet brass is 23 gauge, or .022 inches. Older standard weight instruments may measure closer to .022 inches, but this discrepancy may be due more to the difference in manufacturing techniques as Bach changed from hand-hammering to pressure-forming their bells. Performers using lightweight bells may notice faster response and a more brilliant sound, as lightweight bells will tend to accentuate higher overtones more strongly. Projection is very direct and focused. Lightweight bells are marked with a 5 under the mandrel designation.

Heavyweight: Bach's heavyweight bells are made from 21 gauge sheet brass, or a thickness of .028 inches. These bells are very stable at high volume levels but have less "lively" sounds due to a stronger fundamental in the tone. Heavyweight bells will have an " $\mathrm{H}$ " stamped after the mandrel number.

\section{Bell Bead}

All of Bach's trumpets have a metal wire soldered into the bell bead. This helps with both structural integrity and sound production and projection. There are differences in both the bead and the wire depending on the type of bell and type of instrument.

Round Bead: Most of Bach's trumpets have a round bead. This type of bead aids in balanced projection and response.

French Bead: A "French bead" is flatter than the more modern round bead and can be found on the French-Besson style instruments as well as early Bachs. A French bead offers more pointed articulations and can have a "cleaner" tone.

Brass Rim Wire: Most Bach trumpets will have a brass wire soldered into the bead. A brass wire gives the instrument a traditional tone with balanced overtones.

Steel Rime Wire: Bach's Artisan line of trumpets have a steel wire in the bell bead. A steel wire can accentuate higher overtones in the sound, making the trumpet seem more "brilliant." 
Because of this, an instrument with a steel wire can sound louder, making sound production more efficient.

\section{$\underline{B e l l ~ M a n d r e l ~ N u m b e r s ~ a n d ~ D e s c r i p t i o n s ~}^{4}$}

Bach's bell mandrel numbering system is assigned according to the order it was designed and not according to the size of the mandrel or playing characteristics, thus the numbering system has no function other than separating different bell profiles.

\section{Bb Trumpet Bells}

25: This bell is standard on a large bore trumpet. The slow flare of this bell balances a larger bore well and gives the instrument a very focused and direct sound.

37: The standard bell on Bach's medium-large bore Bb trumpets. It has a medium taper which gives this bell a compact, balanced sound and can be used comfortably in all settings.

38: This bell is standard on a medium bore instrument. It is similar to the 37 but players often find higher volume levels are less accessible.

43: A bell with a slow taper. Because this bell profile is very narrow, the player can experience a tighter blowing instrument and a brighter sound. It is often built as a lightweight bell which further contributes to the brightness. Most frequently found in jazz and commercial settings.

65: This bell has a faster taper than the 72 for an even darker sound; this bell flares so quickly that it can give the trumpet a sound similar to a cornet.

\footnotetext{
${ }^{4}$ Vincent Bach, Trumpet and Trombone Inventory Catalogue, (Elkhart, IN: Conn-Selmer Inc.), 18.; "Bach Trumpets - Bells," Bach Loyalist, 2006, accessed April 5, 2017, http://www.bachloyalist.com/bach-trumpets-bells/.
} 
72: This bell has a fast taper giving the instrument a dark, solid tone. This bell is often built as a lightweight bell to balance the thickness of the sound. Due to the depth of sound, this bell works well in a symphonic setting.

\section{C, D and Eb Trumpet Bells}

These bells are the same profile for all trumpets, but cut shorter for the higher pitched instruments.

229: This bell tapers slowly, giving it a compact, colorful, and brilliant sound. It works well for orchestral players because the sound cuts through an ensemble efficiently. Blow resistance is higher than some other bell profiles.

236: Standard on Bach's D trumpets, this has an even slower taper than the 229, and is very focused.

238: Often paired with Bach's "Vindibona" (conical) bore, this bell does give a trumpet a sound similar to a cornet. As a result, the tone does not project well in a symphonic setting.

239: The standard bell on a $\mathrm{C}$ trumpet. An even, faster taper than the 229 gives this bell a warmer sound, and is appropriate for both orchestral and solo performance.

256: A thick, dark sound characterizes this bell, and will make a $\mathrm{C}$ trumpet sound and play most like a $\mathrm{Bb}$ due to its very fast taper. However, the irregular taper can make intonation irregular as well. 


\section{$\underline{\text { Bach Stradivarius Leadpipes }}^{5}$}

\section{Construction}

Standard: Standard leadpipe construction involves both the leadpipe and the upper tuning slide assembly being connected by a larger ferrule soldered to the end of the leadpipe. Blow resistance is even and balanced throughout all registers, allowing for crisp articulations. This construction is the industry standard for piston trumpets.

Reverse: Reverse construction leadpipes are longer than standard pipes, entering directly into a larger upper tuning slide pipe. Reverse leadpipes eliminate the gap created between a standard pipe and tuning slide allowing for an uninterrupted airflow into the valve section. Players may experience the upper register feeling more resistant with this setup, and the altered blow resistance can make articulations less efficient.

\section{Bb Trumpet Leadpipes}

Bach's leadpipes will be stamped at the hexagonal receiver with the mandrel number. Only the 25 and $25 \mathrm{C}$ will have no marking, as they are the standard pipes for Bach's Bb instruments.

6: A tightly blowing, uncommon leadpipe.

7: This is one of Bach's oldest leadpipes, and what used to be the standard pipe on $\mathrm{Bb}$ trumpets. It has a dark tone and low blow resistance due to a fast taper.

25: The 25 pipe is the standard for Bach's Bb trumpets. The opening venturi on Bach's pipes are 0.345 inches. It has balanced tone, articulation, and resistance for Bach's medium bore setup.

\footnotetext{
${ }^{5}$ Vincent Bach, Trumpet and Trombone Inventory Catalogue, (Elkhart, IN: Conn-Selmer Inc.), 18.; "Bach Trumpets - Leadpipes,” Bach Loyalist, 2006, accessed April 5, 2017, http://www.bachloyalist.com/bach-trumpetsleadpipes/.
} 
25-O: This pipe is standard on Bach's XL bore and lightweight 72 trumpets. The pipe is cut slightly later on the mandrel for a larger venturi of 0.349 inches, giving it slightly less blow resistance.

25LR: The reverse construction version of the 25 pipe.

43: A free blow and a bright sound characterize the 43 pipe. This leadpipe is used frequently in jazz and big band settings; the brightness may not be appropriate for symphonic work.

43LR: The reverse construction of the 43 pipe.

44: This pipe is unique in that it is made from nickel silver, not yellow brass like Bach's other leadpipes. As a result of the harder metal, it has an even brighter sound than the 43 pipe.

\section{C, D, and Eb Trumpet Leadpipes}

Because reverse leadpipes on $\mathrm{C}$ trumpets are cut shorter than $\mathrm{Bb}$ pipes, a spacer has to be soldered to the end of the leadpipe so the upper tuning slide arm may seal over the pipe. This added mass has adverse effects for many players including irregular intonation, tone, and blow resistance over different registers.

6/6R: A shorter version of the $\mathrm{Bb} 6$ pipe, cut for $\mathrm{C}$ trumpet length.

7C: One of Bach's original C trumpet pipes. It has a dark sound and low blow resistance.

7R: The reverse construction version of the $7 \mathrm{C}$ pipe.

25A: A slightly longer pipe than the $25 \mathrm{C}$, this pipe will have less resistance and improved intonation over the $25 \mathrm{C}$. It is named for former Cleveland Orchestra principal trumpet player Bernard Adelstein. 
25C: This is the standard leadpipe for Bach's $\mathrm{C}$ trumpets. Its blow resistance, slotting, intonation, and tone are all very balanced.

25H: The $25 \mathrm{H}$ pipe is a shortened $25 \mathrm{C}$ pipe; it is so short that a spacer must be soldered inside the tuning slide ferrule to lengthen the pipe. This leadpipe has a very free feel and gives the instrument an open, thick sound, but intonation can be imprecise as a result. The " $\mathrm{H}$ " is named after former Chicago Symphony Orchestra principal trumpet player Adolph Herseth, though Herseth mostly used a Mount Vernon era Bach C trumpet with a 25 pipe. ${ }^{6}$

25R: The reverse construction version of the $25 \mathrm{C}$ pipe.

25S: Simply a full length $\mathrm{Bb} 25$ leadpipe, this makes the $\mathrm{C}$ trumpet feel more like a $\mathrm{Bb}$ than any other pipe. The sound is rich and blow resistance is very open. Due to the length, the tuning slide only pulls 3/4 of an inch. The "S" represents former Boston Symphony Orchestra principal trumpet player Charles Schleuter.

43C: This pipe has a more open feel than the standard 25C.

43R: The reverse construction version of the $43 \mathrm{C}$.

44C: This pipe has a slower taper than the $43 \mathrm{C}$ giving a brighter sound. Slotting is more forgiving with a larger venturi.

44R: The reverse construction version of the $44 \mathrm{C}$.

\footnotetext{
${ }^{6}$ Roy Hempley, "Resurrection of a Chicago C or How I Came to Play Like Bud Herseth,” Vincent Bach's World, 2001, accessed April 12, 2017, http://www.vincentbachsworld.com/index_Frames.php?iframe=Other\%20Aricles\%20and\%20Tidbits/Resurrection $\% 20$ Of\%20A\%20Chicago\%20C/Resurrection\%20Of\%20A\%20Chicago\%20C.htm.
} 


\section{$\underline{\text { Common Stradivarius Models }}^{7}$}

Bb Models (Available in reverse leadpipe "LR" and lightweight "LT" variations.)

18037: Bach's most popular trumpet, and best setup for playing in all situations due to an excellent balance of playing characteristics. It has a medium-large bore, 37 bell, and \#25 leadpipe.

18043: This model has the 43 bell, \#25 leadpipe, and a ML bore. Appropriate in commercial and jazz settings, the sound is very bright and may not be suitable for symphonic performance.

18072: With a \#25 leadpipe and 72 bell, this trumpet is most often found in the lightweight option to balance the darkness of the bell setup, and is popular with orchestral players.

\section{Models}

C180L239: This model is Bach's standard C trumpet setup with a large bore, 239 bell, and \#25C leadpipe. Like the 18037, its balanced tone, slotting, articulations, and blow resistance make it useable in many situations where a $\mathrm{C}$ trumpet is required.

C180L229W30: Commonly found in American orchestras, this trumpet has a 229 bell and a 25H leadpipe. The balance of a very open H pipe and the direct, brilliant sound of the 229 bell fit the needs of a principal orchestral player well.

C180SL229CC: Bach created this "Chicago" C trumpet to closely resemble the instruments built in the 1950's for the Chicago Symphony Orchestra trumpet section. However, the wrap, leadpipe, bell bead and wire, valve cluster, and bracing are all different from those instruments. It features wide bracing, a lightweight 229 bell and a version of Bach's \#25C leadpipe. This

\footnotetext{
7 “Conn Selmer: Professional Trumpets,” Vincent Bach, 2017, Conn-Selmer, Bach Brass, accessed April 5, 2017, http://www.bachbrass.com/bach/instruments/trumpets/professional.; "Bach Trumpets - Models," Bach Loyalist, 2006, accessed April 5, 2017 http://www.bachloyalist.com/vincent-bach-trumpet-models/.
} 
setup accentuates high overtones very strongly, and with its small profile leadpipe, the sound can be bright and almost brittle for some players.

C180SL229PC: Bach's "Philly" C trumpet is not modeled after trumpets used in Philadelphia, but is the "Chicago" C trumpet built with a standard weight bell for the Philadelphia Orchestra trumpet section. The sound is slightly more stable than the Chicago's due to the bell weight.

\section{Eb Model}

189: Bach's standard Eb/D setup has a medium-large bore, 239 bell, and a reverse 25 leadpipe. While the bell is fixed, there are two sets of slides for tuning the trumpet to Eb and D. This has the wrap and bell length of a $\mathrm{C}$ trumpet, but due to the traditional 180 degree tuning slide bend, this is not considered a Schilke-style "long-bell" instrument.

\section{$\underline{\text { Bach's Artisan Collection }}^{8}$}

In 2010, Bach introduced their "Artisan" line of trumpets. These trumpets are meant to more closely resemble their Mount Vernon and early Elkhart production era counterparts. Some Artisan models have proprietary bells and leadpipes developed specifically for this line. Features consistent with each model are:

$\sim$ Two-piece valve casings with nickel-silver balusters

$\sim$ Wide-foot leadpipe/bell bracing (Larger brace surface area contacting bell and leadpipe)

$\sim$ French bead bell rim with a steel rim wire

$\sim$ One piece, side-seam bell construction

$\sim$ Both brass and plastic valve guides

$\sim$ Enhanced radius slide ferrules

$\sim$ Unique engravings and serial number designation

$\sim$ Heritage pinky ring design

\footnotetext{
8 "Conn Selmer: Professional Trumpets," Vincent Bach, Conn-Selmer, Bach Brass, 2017, accessed April 5, 2017, http://www.bachbrass.com/bach/instruments/trumpets/professional.
} 


\section{Bb Models}

AB190: The original Artisan Bb trumpet. It has a medium-large bore, proprietary bell and leadpipe, and plays similar to a 37 model.

19037: Similar to the AB190 but with a \#25 leadpipe and 37 bell, this is essentially the Artisan version of Bach's standard Stradivarius model 37.

LR19043B: This instrument is similar to the standard medium-large bore Stradivarius 43, however the bell material is actually bronze, not gold brass, and is enlarged to 5 inches in diameter at the flare and a reverse \#25 leadpipe.

LT1901B: Different than any standard setup in Bach's lineup, this trumpet has a medium-large Bore, standard weight body, lightweight large 5" \#1 bronze bell, bronze balusters, \#43 leadpipe, and braceless tuning slide.

LT190L1B: The large bore version of the LT1901B.

\section{Trumpet Model}

AC190C: Bach's only Artisan C trumpet model. The bell and leadpipe are proprietary, but the profile of the bell and sound characteristic are similar to a 229, and the leadpipe is the same length as a $25 \mathrm{H}$. This trumpet has a large bore valve section.

\section{Eb and D Trumpet Models}

AE190: Bach's “short bell” Artisan Eb trumpet, it has a large bore and a fixed bell. The large bore can make this $\mathrm{Eb}$ feel more like a $\mathrm{C}$ trumpet and gives it a mellower sound more characteristic of a larger instrument, making it suitable for larger ensemble work. 
ADE190: This convertible "long bell" instrument comes with both an Eb and D bell, and a set of $\mathrm{Eb}$ and $\mathrm{D}$ slides. The bore size is a smaller .450, making it more nimble than the AE190 and giving it a smaller, more compact sound.

\section{Piccolo Trumpet Model}

AP190: Bach's Artisan piccolo trumpet model, it has a "long bell" design and a .450 bore. This instrument comes with four leadpipes: two cornet shank pipes in $\mathrm{A}$ and $\mathrm{Bb}$, and two trumpet shank pipes in $\mathrm{A}$ and $\mathrm{Bb}$. 


\section{Chapter 2: The B\&S Brand $^{9}$}

B\&S is owned by the European company Buffet Crampon Deutschland $\mathrm{GmbH}$; for comparison purposes, Buffet Crampon is much like Conn-Selmer in the US, a large parent company that owns several smaller manufacturers. B\&S trumpets are manufactured in the JA Musik complex in Markneukirchen, Germany where many different manufacturers produce brass instruments. These trumpets are designed to compete with, if not directly copy, Bach trumpets, and for most of their lineup the components are identical in labeling, design, and playing characteristics. B\&S is the only foreign manufacturer included in this document, and it was chosen because of the similar design elements, build quality, and sound. Many players actually prefer the B\&S version to their Bach counterpart, and $\mathrm{B} \& \mathrm{~S}$ trumpets can be found in many professional performing groups and orchestras around the world.

\section{Bb Trumpets ${ }^{10}$}

Challenger I 3137: The "Bach 37" of B\&S's lineup, the Challenger I line has an extralightweight yellow brass 37 bell. The leadpipe is gold brass, and the valve section is a one piece, yellow brass, medium-large .459 bore block. Identical to the Bach 37 , aside from the exceptionally lightweight bell, this instrument is a traditionally balanced, "all-around" instrument, however the tone may be too brilliant for some situations.

Challenger II 31372: The Challenger II series is nearly the same as the Challenger I, but with a much heavier gauge brass bell more typical of traditional German trumpets. The leadpipe and bell have very slightly different tapers to balance the heavier instrument, but still mimic the Bach bell and leadpipe profiles. This instrument is available with a standard or reverse construction \#25 leadpipe, and a standard or lightweight yellow or gold brass \#37 bell. Due to the heavier gauge metal for the bell and leadpipe, the sound of the Challenger II instruments may be more typical than the Challenger I.

\footnotetext{
${ }^{9}$ JA Musik, The B\&S Challenger Trumpet Line Inventory Catalogue, (Markneukirchen, Germany: Buffet Crampon Deutschland $\mathrm{GmbH}$ ).

10 “B\&S Trumpets," Buffet Crampon, 2016, accessed April 6, 2017, http://www.b-ands.com/en/instruments/trumpets/.
} 
Challenger II 31252: Virtually copying the Bach Stradivarius 18025, the 31252 offers a 462 inch large-bore valve section with a bell similar to a Bach 25 mandrel.

Challenger II 31722: Nearly identical in sound and construction as the Bach Model 72, this instrument has a .459 medium-large bore, 72 yellow brass bell, and \#25 leadpipe. It is available with a reverse construction leadpipe and a gold brass bell.

Challenger II 31432: B7S's version of the Bach 43, this instrument features a medium-large bore and a 43 yellow brass bell. Options include a reverse construction leadpipe and a gold brass bell, as well as an even heavier gauge bell option. This bell profile like the Bach 43 can be exceedingly bright, and the heavier metal can balance the strident tone this instrument produces.

\section{Line Bb Trumpets}

B\&S's X Line are instruments designed with the collaboration of recording artists, solo performers, and other established professional musicians. Often, models incorporate the name of the performer for which it is designed, essentially making these trumpets "Signature" models.

eXquisite EXB: This instrument is the result of coordination with Hollywood Studio musician Malcolm Mcnab, and was named after his debut album, exquisite: The Artistry of Malcolm $M c N a b$. A medium .444 inch bore assists with an efficient upper register, and the lightweight yellow brass bell with a flat, French bead gives this instrument quick response and a bright, commercial sound.

JBX: The JBX was developed with Broadway musician Chris Jaudes. This instrument was built to project through a pit and handle both heavy upper register and chamber-type ensemble playing. It features a medium-large bore and a lightweight yellow brass 43 bell with a flat, French bead. The leadpipe is unique on this instrument; it is a shortened reverse leadpipe and works on the same principal as the Bach $25 \mathrm{H}$ pipe. By shortening the pipe itself, slotting is more forgiving and the sound can be thicker throughout all registers. 
DBX: This unique instrument's bells are modular in design. The DBX comes with two \#43 lightweight bells, removable via a screw brace. One bell is made of yellow brass and has a French bead for commercial and jazz style playing. The second bell is manufactured in gold brass and has a traditional round bead for symphonic style performance. It has a large .462 inch bore valve section and a reverse construction \#25 leadpipe.

MBX2: A redesigned version of the original MBX designed with French solo and studio artist Christian Martinez, the leadpipe and tuning slide have been modified. The MBX2 features a .459 medium-large bore and a lightweight 72 bell with a French bead. The top and bottom valve caps are heavier to add stability, and the tuning slide is lightly braced with sheet metal instead of the traditional post connecting the top and bottom slide legs. This is a stable, thick-sounding instrument.

MBX3: B\&S's newest $\mathrm{Bb}$ trumpet, it was also designed in collaboration with Christian Martinez, and intended to be a versatile, custom level instrument. It features a lightweight gold brass 43 bell with a flat, French bead. The bore is generally medium large, but modified at points to improve response and clarity of articulations. The instrument comes with two sets of top and bottom valve caps, heavy and lightweight, to change sound and response.

\section{Trumpets}

Challenger II 3136: This model is nearly identical in build, sound, and playability to a large bore Bach Stradivarius C trumpet with a 229 bell and 25C leadpipe. Options include a reverse leadpipe, a shorter $25 \mathrm{H}$ style leadpipe, sterling silver bell and leadpipe, or gold brass bell.

eXquisite EXC: The companion to the eXquisite EXB, this instrument was also designed with Malcolm McNab. It features a medium-large bore and a lightweight, yellow brass, French bead bell. B\&S does not provide any information about the bell or leadpipe profiles other than the leadpipe is standard construction and the bell is slightly larger than standard. This model is very nimble and controlled, and would be used more comfortably as a solo trumpet rather than an orchestral instrument. 


\section{Eb/E/D Trumpets}

31162: The standard long-bell Eb/D setup, it has a .453 bore, yellow brass bell, and separate bells and slides for tuning the trumpet to both $\mathrm{Eb}$ and $\mathrm{D}$. B\&S's higher keyed instruments are more popular than their large trumpets and offer very balanced, consistent sound, articulation, and intonation qualities.

Challenger I 3117JH: This instrument can be tuned to either Eb or E using the two sets of bells

and slides. It also has a $4^{\text {th }}$ valve for added range, making this instrument versatile enough to play many $\mathrm{Bb}$ and $\mathrm{C}$ trumpet parts. It has an extra-large .465 bore which makes this instrument free blowing with a wide sound, but is balanced with a smaller 4.5 inch yellow brass bell. A D bell and slides are available as an option.

eXquisite EXE: The Eb/E companion of the other Malcolm McNab eXquisite instruments, this trumpet is similar in construction to the 31162 - a long bell convertible instrument - but with a smaller .448 bore and French bead. Intended for the Haydn and Hummel solo performer, the smaller bore and French bead gives this instrument a more agile feel, more secure intonation, and a sound more appropriate for solo and chamber performance.

\section{Piccolo Trumpet}

31312: The B\&S piccolo trumpet offering is unique among professional long-bell models in that it features an extra-large .465 inch bore. The bore size makes this instrument very free blowing, but such an unrestricted airflow may not always be advantageous for extreme upper register work. Alternatively, the large bore gives this trumpet a rich sound more characteristic of a short bell instrument, but with the intonation advantages of a long bell model. 


\section{Chapter 3: The Getzen Company ${ }^{11}$}

Getzen has been producing quality instruments since the 1940's, and their product line has undergone many changes as ownership of the company has changed. The company also owns and operates Allied Supply Company, the largest band instrument repair and supply business in the United States, and a custom instrument division, Edwards Instrument Company. As with B\&S, Getzen's trumpet line includes several models that essentially copy Bach Stradivarius instruments in label and sound, as well as some custom and artist designs.

\section{Getzen Valves}

Every manufacturer in this document uses an alloy for their valve pistons called Monel. Monel is a family of nickel alloys that are very resistant to corrosion and incredibly hard due to their high nickel content. In pure form, Monel is actually harder than nickel, a characteristic ideal for brass valves to protect against wear. However, as valve ports are brazed (a process used to fuse metals together under extreme heat) to the pistons, the Monel reacts to the heat and becomes much softer. As a result, Monel valves feel more organic to the performer, but also have a shorter useable life. Typical valves are Monel plated brass tubes, but Getzen uses nickel tubes that are also nickel plated, making an incredibly hard, smooth valve that if cared for properly will last several lifetimes. Because Getzen uses this process, they guarantee their valves for the life of the instrument.

\section{Getzen Bells $^{12}$}

As manufacturers look for more efficient and cost-effective ways to produce larger quantities of instruments, certain techniques used to make different components are changed and modernized. One of the most significant changes to brass production is how bells are created. For hundreds of years the only way to produce a bell was to hand-hammer a sheet of metal on a steel mandrel,

11 “Getzen History," Getzen Co., 2008, accessed April 7, 2017, http://getzen.com/inside/history.shtml.

12 "What is a Hand Hammered Bell?" Getzen Co, March 10, 2009, accessed April 7, 2017, http://www.getzen.com/gazette/2009/03/10/what-is-a-hand-hammered-bell/. 
and then spin that shape on a lathe for further hammering and shaping. This resulted in "tempered" or work-hardened brass that gives the bell certain acoustic characteristics. Modern mass-production instruments now use a much faster process to shape the brass in this initial stage called "pressure-forming." The sheet of brass is essentially stamped into shape by a hydraulic press, and then spun on a lathe for small adjustments to the shape using much smaller hammers and tools. Pressure-formed bells are much more consistent, but lose some of the acoustic characteristics of a hand-hammered bell as a result. Getzen is the only mass-production company that still hand hammers bells for their professional instruments, and as a result their instruments can often have sound character not found in other trumpets. Additionally, Getzen's sterling silver bells are hand-hammered from a sheet of silver, a technique unique to Getzen, not electro-plated on a mandrel.

\section{Getzen's Custom and Artist Model Instruments ${ }^{13}$}

All of Getzen's professional instruments include a true hand-hammered yellow brass bell, heavyweight two piece valve casing with nickel balusters, nickel valves, and nickel outer slide tubes unless otherwise marked.

\section{Bb Trumpets}

3050: The 3050 is congruent with the classic medium-large bore Bach 37, and Getzen's \#125 leadpipe and \#137 yellow brass bell directly copy the playing characteristics of that instrument. The result is a trumpet that can be used comfortably in all playing situations due to the balanced sound and blow resistance. This instrument is available with an L .462 inch bore, gold brass bell, reverse construction leadpipe, and rounded tuning slide.

3051: Getzen's $3051 \mathrm{Bb}$ trumpet in many ways mirrors Bach's 72 model; it has a \#125 leadpipe, \#172 heavyweight gold brass bell, and a medium-large .459 inch bore. This setup typically has a standard or lightweight yellow brass bell; the Getzen's bell is heavier and darker making this instrument almost exclusively appropriate for symphonic playing or solo work due to a dark tone

\footnotetext{
13 “Getzen Trumpets," Getzen Co., 2016, accessed April 7, 2017, http://getzen.com/trumpet/.
} 
quality and open blow of the large bell. Options for this model include a reverse construction leadpipe, L .462 inch bore, and rounded tuning slide.

3052: The 3052 model is intended to be used in commercial or large jazz band settings, however the large .462 inch bore, reverse leadpipe, round tuning slide, and standard weight \#137 bell are peculiar options for use in these situations. This instrument has the option of a medium-large bore, lightweight 72 yellow brass bell, and standard tuning slide. The options will brighten this instrument's sound and make it more secure; these alternatives would make it a more appropriate trumpet for use in the intended musical circumstances.

3001 Artist Model: The 3001 was originally the "Eterna Severinsen" trumpet, designed with virtuoso trumpet player Doc Severinsen. After Severinsen left the company as an endorser, this model was renamed the 3001. It features a medium-large bore, a \#137 heat treated bell, and a proprietary heat treated leadpipe with slightly more resistance than standard. This heat treatment, or annealing, is where metal is heated quickly to a high temperature in order to soften the metal. This treatment can have different effects on this instrument depending on where the annealing is done. This trumpet has a bright sound and quick response, making it appropriate for lead players and performers who need a searing, commercial sound and frequently work in the upper register.

3003 Genesis: The Genesis was created when the heavy, sheet-braced Monette instruments were popular in the 1990's. Its large .462 inch bore, sheet-braced tuning slide and bell bend, extralarge 5 1/8 inch bell with a large throat, and ovate tuning slide make for a dark, stable, and open, almost trombone-like sounding trumpet. This instrument features a modular leadpipe system that allows the player to adjust blow resistance by choosing one of the two provided "Standard" or "Open" pipes. 


\section{Trumpets}

3070: Intended to be an alternate for the standard Bach $229 \mathrm{C}$ trumpet, this model has a large bore, \#125 leadpipe, and \#29 bell. A reverse construction leadpipe is optional, as is a rounded tuning slide. This model is intended for the orchestral musician, and its brilliant, direct sound and secure slotting are appropriate for symphonic playing.

3071: This model is the same as the 3070, but the bell is a heavyweight gold brass version of the \#29 profile. This makes the instrument more stable and gives it a darker sound, but may not be the most efficient setup for ensemble playing. It has an optional reverse leadpipe and rounded tuning slide.

3072: The 3072 features Getzen's version of the Bach 239 bell, the \#39, in yellow brass. This model has a \#125R reverse construction leadpipe and rounded tuning slide. The combination of a less brilliant bell, more open leadpipe and less resistant tuning slide make this instrument play more like a $\mathrm{Bb}$ trumpet. Getzen claims in their literature that this setup makes this model a lighter and more agile instrument for chamber playing, but the playing characteristics of the components on this trumpet may make the sound and instrument response too dark and open for chamber work.

\section{Piccolo Trumpet ${ }^{14}$}

940 Eterna: The 940 is the only Eterna model in the Getzen offering considered to be a professional instrument. It features a small .420 in bore and short-bell design. Getzen began offering the instrument with Blackburn trumpet shank leadpipes, and these greatly improved the sound, playability, and intonation of this instrument. Short-bell piccolo trumpets produce a large, warm sound, and can be used comfortably in all settings.

3916: Getzen's Custom Series piccolo trumpet is a long-bell design with a medium .451 inch bore valve section. It has a two-piece solid copper bell, and a set of $\mathrm{Bb}$ and $\mathrm{A}$ leadpipes with a

\footnotetext{
14 “Specialty Trumpets," Getzen Co., 2016, accessed April 7, 2017, http://getzen.com/trumpet/specialty/.
} 
trumpet shank. The long-bell design assists with upper register work, but the sound will not be as present and warm as a short-bell instrument. 


\section{Chapter 4: Edwards Instrument Company ${ }^{15}$}

Edwards Instrument Company is the custom division of its parent company, Getzen. Edwards' instruments are unique in that they offer mostly modular instruments. Leadpipes, bells, and tuning slides are interchangeable; combination options are in the thousands for these instruments. Many of the parts found on Edwards instruments are the same that the Getzen Custom Series trumpets use including some leadpipes, valve sections, certain bells, and tuning slides. There are more options available on Edwards trumpets than found on Getzen trumpets. Edwards advertises itself as a completely custom shop that fits every component of their trumpets to the individual player - musicians can visit the shop and be "fit" to their instrument by the Edwards team, all of whom are professional musicians as well as instrument makers.

Edwards does not publish many specific measurements or playing characteristics of their components. They prefer not to share this information so as not to influence musicians' decisions during the custom fitting process. Information about how these components perform can only be estimated based on the little information Edwards provides. Edwards' components are not necessarily modeled after Bach components.

\section{Bell Materials $^{16}$}

Yellow Brass: The standard brass for all trumpet components. Edwards' brass alloy is $70 \%$ copper and 30\% zinc. It produces a good balance of brilliance, projection, and response.

Bronze: Edwards' "bronze" material is technically red brass - true bronze is made of copper and tin - Edwards uses an alloy of $90 \%$ copper and $10 \%$ zinc. Softer than yellow brass, red brass bells absorb sympathetic vibrations and produce a dark, mellow sound with less projection.

\footnotetext{
15 “Frequently Asked Questions,” Edwards Instrument Company, 2017, accessed April 7, 2017, http://www.edwards-instruments.com/edwards/faq.php.

16 “Edwards Trumpets," Edwards Instrument Company, 2017, accessed April 7, 2017, http://www.edwardsinstruments.com/trumpet/bells/index.php.
} 


\section{Bell Weights}

21 Gauge: Edwards' heavyweight bells are made from 21 gauge sheet brass, or a thickness of .028 inches. These bells are very stable at high volume levels but have less "lively" sounds due to a stronger fundamental in the tone.

22 Gauge: Edwards' standard weight sheet brass is 22 gauge, or .025 inches in thickness. This weight offers a balance of response and projection.

23 Gauge: The thickness of Edwards' lightweight sheet brass is 23 gauge, or .022 inches. Performers using lightweight bells may notice faster response and a more brilliant sound, as lightweight bells will tend to accentuate higher overtones more strongly. Projection is very direct and focused.

\section{Bell Treatments}

Tempering: Tempered bells are simply hand-hammered bells with no other process applied to the brass. Secure slots and a balanced sound are characteristics of a hand-hammered bell.

Heat Treating: During heat treatment, bells are applied to direct, high heat in small areas of the bell, softening it in spots. This softening will make the bell less responsive and allow for softer "slotting."

Annealing: Annealed bells are treated with high heat like heat treated bells, but the heat is applied to the entire bell. This process can darken the sound and make slots even more forgiving.

\section{Edwards Bells}

Bells on these instruments are completely interchangeable. The bracing is based on a screw-in design. Edwards bells also feature a special "harmonic post" that connects the bell to the valve block. By tightening or loosening this post the player can brighten or darken the sound slightly. 


\section{Bb Bells}

K Bell: This bell has a medium large "throat," meaning it flares at a medium rate to the end with a 4 7/8 inch flare. This is Edwards' most versatile bell.

M Bell: This bell flares more quickly to the standard $47 / 8$ inch diameter. A faster flare will give this bell a mellower, darker sound.

XK Bell: This bell has the same medium large throat as the $\mathrm{K}$ bell, but flares to a $51 / 8 \mathrm{inch}$ diameter. The larger flare can result in a larger, but more spread sound. The XK bell is standard on the Generation 3 and $3 X$, but must be specially made for the Generation 2 models.

\section{Trumpet Bells}

C3 Bell: This bell has a large throat and a standard 4 7/8 inch flare. It is similar in sound character to a Bach 239 - richer and less direct than a 229.

C2 Bell: The $\mathrm{C} 2$ has a medium large throat and a standard $47 / 8$ inch flare. The sound of this bell is more direct and brilliant than the $\mathrm{C} 3$, similar to a Bach 229 bell.

\section{Tuning Slides ${ }^{17}$}

These slides are available on the Generation 2 models. Bb slides come in large or medium large bore sizes, $\mathrm{C}$ slides are only available in large bore.

Standard Crook: The standard slide bend is between a square and round bend. It produces a balanced sound, stable articulations, and medium resistance.

\footnotetext{
17 “Edwards Trumpets," Edwards Instrument Company, 2017, accessed April 7, 2017, http://www.edwardsinstruments.com/trumpet/options/tuning_slides.php.
} 
Square Crook: The square crook offers slightly more resistance, which results in crisper and faster articulations. The sound may be slightly more brilliant as well.

Round Crook: A slide with a rounded crook has a very open blow, and as a result articulations can be less responsive and less pointed. The sound quality with this slide can be less direct as well.

Generation 3 and $3 \mathrm{X}$ slides feature an ovate crook. It has a more aggressive oval shape to the crook with a single sharp bend. These slides create a very free-blowing instrument with the benefit of crisp articulations similar to the square crook. Slots with this slide are very fluid, not as rigid as with a traditional tuning slide.

\section{Edwards Leadpipes $^{18}$}

The ILS (Integral Leadpipe System) on Edwards trumpets consist of an outer retaining tube soldered to the valve block that houses the leadpipe itself, allowing the leadpipe to be changed quickly at any time without the use of any tools. All Edwards instruments have a modified hidden-reverse construction as a result of this setup. Each model of leadpipe has the same venturi for a $\mathrm{Bb}$ or $\mathrm{C}$ trumpet, the tube is simply cut shorter for a $\mathrm{C}$ trumpet.

\section{Leadpipes}

BD1: A medium leadpipe with an opening venturi of .340 inches. It creates a fairly bright sound and is appropriate for jazz or commercial settings.

D2: Though it has a larger opening venturi of .343 inches, the taper of the pipe is such that it is slightly tighter in blow resistance. A bright leadpipe also appropriate for jazz and commercial playing.

\footnotetext{
18 “Trumpet Leadpipes," Edwards Instrument Company, 2017, accessed April 7, 2017, http://www.edwards-instruments.com/trumpet/options/leadpipes.php.
} 
D3: A venturi of .349 makes this a very balanced pipe useable in all performance settings.

D4: With a large venturi of .351 inches, this pipe has a large sound, but is still colorful enough for use in orchestral work.

D5: Edwards' most open pipe with a venturi .354 inches. This pipe produces an almost hollow sound and is very free blowing.

\section{Instrument Models (Templates) ${ }^{19}$}

Generation 2: Edwards Generation 2 series is the most traditional template available. It features a standard crook tuning slide and bell bend for response, slotting, and sound similar to Bach-style instruments. $\mathrm{Bb}$ instruments can be made with a medium-large or large bore valve block, and $\mathrm{C}$ trumpets are only available with a large bore.

Generation 3: This template features an ovate tuning slide. Slotting is very smooth and the instrument can feel more open than a trumpet with one with traditional tuning slide crook. $\mathrm{Bb}$ models can be purchased in a medium-large or large bore, and $\mathrm{C}$ trumpets are only available with a large bore valve section.

Generation 3X: These instruments are identical in construction to the Generation 3, but standard post bracing is replaced with heavyweight sheet metal bracing at the tuning slide, bell, and leadpipe. It is identical to Getzen's Genesis model, but also offers Edwards' interchangeable bell system.

Generation 4: This model is specifically a fixed style $\mathrm{C}$ trumpet. There are no modular components; it is a setup of the most popular options of Edwards' Generation $2 \mathrm{C}$ trumpets. It features a large bore, yellow brass $\mathrm{C} 3$ bell, and square tuning slide.

\footnotetext{
19 “Edwards Trumpets," Edwards Instrument Company, 2017, accessed April 7, 2017, http://www.edwardsinstruments.com/trumpet/index.php.
} 
Eb Trumpet: Edwards also offers an Eb/D trumpet. It is a long-bell design, and can be made with two types of bells. The yellow brass bell has a more brilliant, direct sound for ensemble playing, and the copper bell is richer and more appropriate for solo and chamber work. 


\section{Chapter 5: Schilke Music Products ${ }^{20}$}

Schilke Music Products has been manufacturing instruments since 1956 when Renold O.

Schilke, a member of the Chicago Symphony Orchestra, began designing his own instruments.

These trumpets are the most unique of all the manufacturers in this document as they do not at all aim to copy Bach Stradivarius trumpets. Schilke instruments are regarded as some of the easily tuneable and playable trumpets ever made. Much as Bach Stradivarius Bb and C trumpets are copied by innumerable manufacturers, Schilke's Eb and piccolo trumpets are the world standard and the template for nearly every professional high pitched trumpet made today.

\section{Bore Sizes $^{21}$}

Schilke's sizes differ slightly from the other manufacturers listed, but retain similar playing characteristics. Bore sizes with most Schilke instruments are nearly irrelevant however, as the bore diameter is more of a "step-bore," or gently conical in design.

M: .450 inches

ML: .460 inches

L: .463 inches

XL: .468 inches

\section{Schilke Bells $^{22}$}

Schilke's labeling system for their bells can be very confusing, and refers to a general shape and size rather than any specific mandrel or measurement. There are two designations for a Schilke bell: a taper shape and size relative to the instrument. Schilke offers seven tapers and five relative bell sizes. Bell sizes range from small to extra-large and are not consistent between keys

\footnotetext{
20 “Our Company,” Schilke Music Products, 2014, accessed April 8, 2017, http://www.schilkemusic.com/our-company/.

21 Schilke Music Products, Inc., Trumpets \& Cornets Brochure, (Melrose Park, IL: Schilke Music Products, Inc.).

22 Jim Donaldson, "Bell and Slide Options," The Schilke Loyalist, 2006, accessed April 8, 2017. http://www.dallasmusic.org/schilke/Bells, \%20slides\%20and\%20finish.html\#Bell\%20labels.
} 
of instrument, but instead are relative within a single key of trumpet. That is, an $\mathrm{M}$ bell will not be the same size on a $\mathrm{Bb}$ trumpet as it is on a $\mathrm{C}$ trumpet.

\section{Bell Tapers $^{23}$}

\#0: A fast taper, very large throat, and standard diameter rim. This bell taper has a dark, fluffy sound.

$\# 1$ : Not as large as the \#0, this taper is still fairly fast and has a large rim.

\#2: A gradual, medium taper with the same large rim as the \#1. This is Schilke's most balanced sounding taper.

\#3: This bell is similar to the \#2, but has a larger throat and a faster taper. Because of the more open design this bell does not produce as much volume as the \#2.

\#4: For Eb and D trumpets, this has a smaller flare and throat for a direct sound and efficient blow.

\#5: This taper is used on Schilke's G and F instruments and has a taper similar to the \#4.

\#8: A very small bell for piccolo and G trumpets, it has a bright, direct sound and very efficient blow resistance.

\section{Tuning Bells}

All of Schilke's trumpets are available in their tuning bell design. With this setup, there is no need to use the tuning slide, the instrument should be tuned completely at the bell. Reynold Schilke believed that in order to achieve perfect intonation, there could be no interruptions to the

\footnotetext{
23 “Trumpets," Schilke Music Products, 2014, accessed April 8, 2017, http://www.schilkemusic.com/products/trumpets/.
} 
bore through the leadpipe. The tuning bell eliminates any gaps in the leadpipe and crook, and instead puts an additional tuning ferrule at the bell tail. As a result, however, the bell is completely unbraced, and the instrument is far more fragile without the structure of the leadpipe and bell braces. Additionally, players may experience "bell flutter," or a disruptive vibration of the bell against the valve block when performing at louder volumes. Compared to traditionally braced instruments, players find the tuning bell setup to be more responsive and even throughout all registers with less blow resistance.

\section{Bell Materials}

Yellow Brass: This is the standard bell material. Like all other manufacturers, Schilke's yellow brass bell offer a good balance of sound and response.

Beryllium: Originally, Schilke's beryllium bells were made out of actual beryllium. However, this metal was found to be a carcinogen and its use was discontinued. Currently, Schilke's beryllium bells are made from pure copper and are electroplated on a mandrel. These bells are incredibly thin and fragile. With the combination of soft copper and light weight, these bells have a rich sound and efficient projection.

Sterling Silver: Electroplated like their copper bells, Schilke's sterling silver bells are slightly thicker and have a different palette of colors. Still rich in tone, these bells are slightly darker sounding and project less.

Copper: Though Schilke's beryllium bells are now in fact copper, Schilke also offers copper bells. The difference with Schilke's copper bells is simply the thickness; beryllium bells are extraordinarily lightweight, and copper bells are a standard gauge. 


\section{Schilke's Original S, X, and C Series Trumpets ${ }^{24}$}

These models are Reynold Schilke's original designs. They are lighter weight than Bach-style instruments, have a reverse-construction leadpipe and tuning slide setup. There are no leadpipe designations or options with Schilke instruments.

\section{Bb Trumpets ${ }^{25}$}

B1: The most popular and balanced of Schilke's Bb trumpets, it has a medium-large bore, and an L bell with the \#1 taper. It is the most free-blowing medium-large bore instrument, and has the richest sound.

B2: Medium-large bore, $\mathrm{M}$ bell, and \#3 taper, this instrument can play fairly tightly and has a bright sound.

B3: A large bore instrument, the $\mathrm{B} 3$ has an $\mathrm{M}$ bell and \#3 taper. This is a very free blowing instrument with a balanced sound due to the smaller bell and open taper.

B4: This instrument's $\mathrm{M}$ bore, $\mathrm{M}$ bell, and tight \#3 taper make this a very tight, bright, small playing instrument.

B5: One of Schilke's most popular instruments, the B5 has a medium-large bore and an ML bell with the \#2 taper. Standard on this model is a copper bell. Slightly more resistance than the B1, the B5 is said to play similarly to a Bach 37 model.

B6: Known as "The Bill Chase Horn," this trumpet was in fact favored by the famous jazz musician. It features an M bore and ML bell with the \#2 taper. Many players find this to be an

\footnotetext{
24 “Trumpets," Schilke Music Products, 2014, accessed April 8, 2017, http://www.schilkemusic.com/products/trumpets/.

${ }^{25}$ Jim Donaldson, "Schilke Bb Trumpets," The Schilke Loyalist, 2006, accessed April 8, 2017, http://www.dallasmusic.org/schilke/B\%20flat\%20trumpets.html.
} 
efficient upper-register instrument with a bright tone. Most B6 models are made with a copper bell standard.

B7: The B7 model comes with an M bore, L bell, and \#1 taper. It is slightly larger in sound than the $\mathrm{B} 6$ and has a darker tone.

$\mathrm{X} 3$ : The $\mathrm{X} 3$ is the largest playing trumpet of the original line. It has a large bore and bell, as well as the large \#1 taper.

\section{Trumpets ${ }^{26}$}

Schilke's original C trumpet designs have never sold well in the United States due to their unconventional sound. Though they are incredibly in tune, the sound of these trumpets may not project through an ensemble with enough color to be the best option for most players.

$\mathrm{C} 1$ : The $\mathrm{C} 1$ has a medium-large bore and \#1 taper $\mathrm{L}$ bell. It is the most balanced of the $\mathrm{C}$ series instruments but can get bright quickly due to the bore.

C3: With a large bore, the $\mathrm{C} 3$ is more comfortable to play at louder volumes, but with the $\mathrm{M}$ bell and \#3 taper, this model is not as efficient in an ensemble and may be better in a solo or chamber setting.

C5: This instrument has the same measurements and components as the $\mathrm{C} 3$, but comes with a different shaped bore in the tuning slide area, slightly smaller for more resistance.

CX: The CX is a large bore instrument with Schilke's L bell and \#1 taper. It is the most free blowing of the $\mathrm{C}$ series.

\footnotetext{
${ }^{26}$ Jim Donaldson, “Schilke C Trumpets," The Schilke Loyalist, 2006, accessed April 8. 2017, http://www.dallasmusic.org/schilke/C\%20trumpets.html.
} 


\section{HD Series Instruments}

The HD series instruments are fairly new to the company, and are, as the name suggests, a "Heavy Design.” These instruments play and sound more like traditional Bach Stradivarius trumpets, and are meant to directly compete with the brand. They feature heavier weight bells, leadpipe, and mouthpiece receiver, as well as a braced tuning slide. The same bell profiles and reverse construction leadpipe remain.

\section{Bb Trumpets}

S22HD: A large bore instrument with the ML bell and \#2 taper. This is a very versatile instrument that can be used in all playing situations.

S23HD: Also with a large bore, the S23HD comes with a smaller M bell and \#3 taper. Darker sounding but also not as efficient in volume production.

S32HD: A medium-large bore and ML bell with the \#2 taper make this an efficient trumpet with a balanced sound.

S33HD: Also with a medium-large bore, this trumpet has the smaller M bell and \#3 taper.

S43HD: The $\mathrm{S} 43 \mathrm{H}$ has a small $\mathrm{M}$ bore, $\mathrm{M}$ bell, and \#3 taper. This is an efficient trumpet for upper register work.

S43HSL-F: Schilke's only "Artist" model, this instrument is a popular jazz and commercial trumpet endorsed by soloist John Faddis. It is identical to the S43HD, but with less mass on the valve slides and a tuning bell configuration. 


\section{Trumpets}

S22CHD: With a large bore and ML bell with the \# 2 taper, this trumpet is excellent for orchestral playing. Many players regard this instrument as a more refined alternative to the Bach 229.

C3HD: The HD version of Schilke's C3, this instrument is slightly more responsive and has a thicker, more traditionally "Bach" sound than the C3.

\section{Handcraft Series}

These two $\mathrm{Bb}$ trumpets are a re-introduction of the famous Martin Handcraft Committee trumpets that were out of production for decades. Reynold Schilke was one of the "Committee" members who helped to design the original model for Martin, and had direct influence on the leadpipe and bell design of that instrument. The result was a trumpet with one of the most recorded sounds of the jazz era, it was used by performers such as Dizzy Gillespie and Miles Davis. With the Handcraft Series, Schilke is attempting to recreate this trumpet and the sound it produced. These instruments are intended primarily for solo and combo jazz performance.

HC1: An XL bore and XL bell with the \#0 taper make this instrument an incredibly open, dark, and "smoky" sounding instrument.

HC2: The same components as the HC1, this model has a copper bell for an even darker, diffuse sound.

\section{Eb Trumpets}

E3L: Almost ubiquitous, the E3L revolutionized Eb trumpet design with its leadpipe and longbell setup. With an M bore and M bell with the \#4 taper, this instrument's intonation, playability, and easy blow resistance became the "benchmark of comparison" for Eb trumpets. Included are a $\mathrm{D}$ bell and slides. 
E3L-4: the 4-valve iteration of the E3L, the extra valve adds a fourth to this instrument's range. Still a medium bore instrument, the E3L-4 comes with the ML bell and \#2 taper for a larger, richer sound more appropriate for ensemble playing. D bell and slides are available but not included with this instrument.

\section{Piccolo Trumpets}

P5-4: As with the E3L, the P5-4 became the piccolo trumpet standard for playability and design. Before this instrument, no other piccolo trumpet was as in tune or useable. It has an M bore and $\mathrm{S}$ bell with the \#8 taper. One cornet shank Bb leadpipe is included that can be pulled out to tune the instrument to A.

P5-4BG: The "Butler/Geyer" version of the P5-4, this instrument simply has a ring on the $3^{\text {rd }}$ valve slide and a hook on the $1^{\text {st }}$ valve slide to assist with intonation.

P7-4: The short-bell offering in Schilke's lineup, the bell has a traditional bend, giving this instrument a slightly broader sound more appropriate for ensemble performance. 


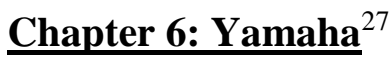

Yamaha's trumpet components are not interchangeable like Bach's offerings; bells, leadpipes, and other components are specific to a particular model. There are three levels of professional trumpets that Yamaha manufactures: 6000 series - professional line, 8000 series - Xeno custom line, and 9000 series - artist line.

\section{0 series}

Yamaha's 6000 series instruments were the company's first foray into the United States professional trumpet market, and sought to copy the country's most popular instruments, the Bach Stradivarius. Of the original lineup that was introduced in the 1980's, only a few are still in production. The body, valve casing, and bells of the 6000 series are all yellow brass unless otherwise noted.

\section{Bb Trumpets}

YTR-6335: This was Yamaha's first trumpet built for professional use. Many characteristics of this model copy Bach components - the bell is similar in profile and sound to a 37, the leadpipe is similar in taper and response to a \#25, and it has a medium-large bore. The 6335 has a gold brass leadpipe, something that Bach does not offer. The gold brass construction is more resistant to corrosion, a problem some early Yamahas exhibited in their leadpipes.

YTR-6345G: This is the large bore, gold brass bell version of the 6335. For players who find the 6335 too bright and restrictive in blow, these variations make for a louder and more stable instrument.

\section{Eb Trumpet}

\footnotetext{
27 “Trumpets - Brass/Woodwinds - Musical Instruments - Products - Yamaha United States," Yamaha Corporation of America and Yamaha Corporation, 2017, accessed April 6, 2017, http://usa.yamaha.com/products/musical-instruments/winds/trumpets/.; Wind Instruments Inventory Catalogue, Yamaha Corporation of America, 2014, (Buena Park, CA: Yamaha North American Edition).
} 
YTR-6610: This convertible Eb/D trumpet has a fixed bell with tuning and valve slides for both keys and a .445 inch bore.

\section{Piccolo Trumpet}

YTR-6810: A short-bell instrument, the 6810 has a single, trumpet shank leadpipe that pulls from $\mathrm{Bb}$ to $\mathrm{A}$. With a small bore of .413 , some players may find this instrument to be very resistant.

\section{Xeno 8000 Series}

In 2014, Yamaha's original Xeno line was updated with some redesigned components to address issues players had with the trumpets, and to integrate design information Yamaha learned from their Artist line. Changes include a slightly different bell profile to improve the sometimes odd slotting of the original models, standard weight valve casing, pistons, and mouthpiece receiver, and an altered water key placement on the tuning slide. Unless otherwise marked, this series features a yellow brass bell, two piece valve casings with nickel balusters, and a gold brass leadpipe.

\section{Bb Trumpets}

YTR-8335II: Yamaha's standard Xeno Bb is the most balanced trumpet in the Xeno line. With moderate blow resistance due to the medium-large bore and conventional bell and leadpipe taper, this trumpet can be successfully used in all playing situations. If a trumpet has the gold brass bell option, the casing will be marked YTR-8335G. Yamaha's gold brass bell will add more depth to the sound by strengthening the lower overtones in the sound; it will tend to be more "dense" sounding than Bach's gold brass bells.

YTR-8345II: This is the large bore version of Yamaha's 8335. 
YTR-8335IIR: This is identical to the 8335, but with Yamaha's reverse leadpipe setup. The leadpipe has significantly less tuning slide pull than both Yamaha's standard leadpipe and Bach's reverse leadpipe; and this is due to a partial sleeve on the leadpipe and more weight on the upper tuning slide leg. The balance of weight across the leadpipe and tuning slide results in a more balanced sound and blow.

YTR-8345IIR: This is the large bore version of the 8335R.

Gold brass bell option: If the trumpet has the gold brass bell option, the casing will be marked with a "G" after the model designation. Yamaha's gold brass bell will add more depth to the sound by strengthening the lower overtones in the sound; it will tend to be more "dense" sounding than Bach's gold brass bells.

\section{Custom Signature Series}

These instruments were developed with specific recording artists and studio, commercial, and jazz playing in mind. They have special bell, leadpipe, and valve blocks which are different than the standard Xeno instruments' components.

YTR-8310Z: Designed with and for commercial recording artist Bobby Shew, this is the second iteration of "the Z horn." It utilizes Yamaha's step bore design which starts at a very small .445 inches and flares continually through the valve section. This gives the trumpet the secure attacks of a small bore instrument and the volume capability of a medium-large bore. To balance the small start to the bore, the instrument has a large bore unbraced tuning slide and a reverse construction leadpipe in gold brass. The valve block is lightweight and all yellow brass, accentuating higher overtones. The bell is a slowly tapered " $Z$ " mandrel with a French bead and 5 inch diameter flare, providing this instrument with a bright, crisp sound.

YTR-8335LA: Designed with Hollywood recording artist Wayne Bergeron, this trumpet has a gold brass leadpipe similar in profile to the "Z," but with a slightly larger venturi to allow for more air and volume. Additionally, the bore of the tuning slide is .462 inches, the same tuning 
slide as a large bore instrument. It has a medium-large bore and a lighter, medium weight, all brass valve block. The bell profile is specific to this model, and has a French bead which can assist in crisper articulations. The LA has a slightly larger bell diameter of 5 inches which can result in a larger and fuller sound. In all, this is a trumpet with a large, brilliant sound, but with enough resistance to maintain accuracy.

YTR-8340EM: Designed originally for solo artist Eric Miyashiro, this trumpet uses many of the same components as the $\mathrm{Z}$ and LA instruments. Yamaha designates this setup as a "multi-bore," which is a slight variation on the Z's step-bore design. It has a gold brass, reverse construction leadpipe and a braced tuning slide. With a lightweight valve block and an oversize 5 1/4 inch bell, this instrument can get bright and loud very quickly.

\section{Trumpet}

YTR-8445II: The 8445 underwent the same "facelift" as Yamaha's Xeno Bb models one year later in 2015, and benefited from the same bell, leadpipe, and construction modifications. It has one bore option, a large .462 inch bore. The leadpipe is similar in sound and blow to a Bach 25C, if not slightly tighter, and the bell profile is similar to a Bach 239 . This results in a balanced, generic $\mathrm{C}$ trumpet appropriate for all playing situations. The bell is annealed, or treated at high

heat, softening the aggressiveness some $\mathrm{C}$ trumpet sounds can have. The gold brass leadpipe and mouthpiece receiver are both heavyweight; this strengthens lower overtones but can also dampen the tone of the instrument. There is also a gold brass bell option for this instrument which can further darken/dampen the brilliant sound many players need in a $\mathrm{C}$ trumpet.

\section{Yamaha Xeno Artist Model 9000 Series}

Yamaha's Artist series Xeno instruments are the highest quality instruments the company produces. Many of them were developed with some of the best classical trumpet players in the United States and use custom trumpet maker Bob Malone's designs. 


\section{Bb Trumpets}

YTR-9335CHSII: The “Chicago" Bb, this instrument was developed with John Hagstrom, $2^{\text {nd }}$ trumpet of the Chicago Symphony Orchestra. Originally, this instrument was designed to incorporate the best elements of vintage Bach Stradivarius trumpets and integrate modern manufacturing techniques and technology. This is the second iteration of the Chicago $\mathrm{Bb}$; the bell, leadpipe, water keys, and bracing were improved upon from the original. The $\mathrm{Bb}$ has a medium-large bore and a Bob Malone MB1 "hidden reverse" construction leadpipe which is very balanced in blow resistance, tone, and response. In Malone's hidden reverse pipe, the tuning slide enters a space over the leadpipe but under a top sleeve. This allows optimal bell brace placement and negates some of the inherent flaws of the original Bach-style reverse construction. The mouthpiece receiver is very short, and weighted towards the mouthpiece, aiding in faster response. The yellow brass, side-seam bell has a unique taper which stays fairly narrow up to the valve section, and then flares aggressively towards the end. While the two-piece nickel and brass valve section is heavier in weight, the pistons are lighter than the standard Xeno line, and the valve stems are hollow, contributing to a more even weight distribution and faster articulation.

YTR-9335NYSII: Originally developed with Robert Sullivan of the New York Philharmonic, Cleveland Orchestra, and Cincinnati Symphony Orchestra, the NYSII was updated in collaboration with Philadelphia Orchestra principal trumpet David Bilger. Retaining the same build qualities as the Chicago, this model has a standard construction Bob Malone MB2 leadpipe which is a slightly more open version of the MB1 found on the Chicago. The bell is very similar to the Chicago's, but with a bottom seam for a different, heavier type of response to articulations.

\section{Trumpets}

YTR-9445CHSII: This model is the C trumpet version of the 9335CHSII, also designed with John Hagstrom, and incorporates many of the same design updates. A feature unique to the 9445CHSII is a tapering bell wall thickness. When a bell is actually hand-hammered and not pressure formed, the process creates a gradual thinning of bell metal as it flares. Yamaha has created a process of mechanical buffing that artificially reproduces this effect. Many believe that 
the unique tone color of vintage Bach $\mathrm{C}$ trumpets is due in part to the graduated bell wall thickness. A flat, French bead is also part of the bell design of this instrument. The 9445CHSII has a hidden-reverse Malone MC1 leadpipe and a large, .462 inch bore. With crisp, nimble articulations and a clear orchestral sound, many players may find this instrument and the others in this series to be ideal audition trumpets. The CHSII is the more brilliant sounding of the three Artist C's.

YTR-9445NYSII: Developed with David Bilger, the "New York" C is the C trumpet partner of the 9335 NYSII. With the same features as the Bb counterpart, this instrument has a large, .462 bore and a standard construction MC2 leadpipe. The sound of this trumpet is slightly thicker than the CHSII, due simply to the different leadpipe.

YTR-9445NYSII-YM: New in 2017, this trumpet is identical to the 9445NYSII except for the bell. When the NYSII was released, members of the Boston Symphony Orchestra trumpet section worked with Yamaha to develop an instrument whose sound would better fit Symphony Hall. The result was designing a bell that retains the same, slow taper up to the valve section, but then flares quickly at the end. The mandrel created is Yamaha's YM bell, thus the model designation for this instrument.

\section{Eb Trumpets}

YTR-9610: Yamaha's custom Eb/D instrument, this trumpet is sold with a set of two bells and slides to tune the instrument to $\mathrm{Eb}$ or $\mathrm{D}$. It features a medium, .445 inch bore, gold brass leadpipe, and yellow brass bell. A Schilke-style long-bell design gives this instrument better intonation and a warmer sound than the 6610 with a more consistent blow across the registers.

YTR-9630: In Eb only, this instrument has a fourth valve to extend the trumpet's range by a fourth. The added tubing along with an oversized five inch bell give this instrument the range and depth of sound making it capable of being used for most $\mathrm{Bb}$ and $\mathrm{C}$ trumpet parts. The .445 inch bore aids in crispness of articulations and agility, and assists with increasing endurance for more demanding parts. 
YTR-9635: Similar in build to the 9610, this instrument can be tuned to Eb or E by changing the slides and bell. The bore is a slightly larger medium-large .459 inch block. This instrument is produced for those who frequently perform both the Haydn and Hummel concerti.

YTR-9636: This trumpet is meant to be the Eb/D companion of the CHS collection of instruments and was designed with John Hagstrom. It has two sets of slides and bells for tuning in both $\mathrm{Eb}$ and D. Yamaha developed a unique "S" shaped MC1 leadpipe which is meant to improve response and intonation over the single bend, long-bell shape. The medium-large .459 bore helps to give this trumpet a larger sound and provide the performer with a freer blow.

\section{Piccolo Trumpets}

YTR-9825: This instrument is the piccolo trumpet companion of the CHS series of instruments, and was developed with John Hagstrom. It can be tuned to A or Bb using two sets of leadpipes: two for A with a trumpet and cornet shank, and two for Bb with a trumpet and cornet shank. A feature unique to this model is a rotary valve that extends the third valve slide an additional whole step, allowing the player to access a low F (concert D) using the $1^{\text {st }}$ and $3^{\text {rd }}$ valves. A short-bell model with a .445 inch bore, this trumpet is surprisingly open and produces a warm sound, similar to early Selmer piccolo trumpets.

YTR-9835: Produced with David Washburn of the Los Angeles Chamber Orchestra, this instrument is the standard, Schilke-style long bell setup, includes four Malone leadpipes in A and $\mathrm{Bb}$ with cornet and trumpet shanks, and has a .445 inch bore. 


\section{Chapter 7: Categories of $\mathrm{Bb}$ and $\mathrm{C}$ Models}

This section aims to collect select instrument models in terms of their best usage. Some instruments are appropriate for multiple categories, and some instrument models are not included in this section at all, either due to the rarity of the instrument or because its use is uncommon. Recommendations are provided for each.

\section{Bb Trumpets}

"All-Around" Trumpets

Bach 18037

Edwards Generation 2

Bach 18072 Lightweight

Schilke B1

Bach AB190

Schilke S22HD

Bach AB19037

Yamaha YTR-6335

B\&S Challenger I 3137

Yamaha YTR-8335

B\&S Challenger II 31372

Yamaha YTR-9335CHSII

B\&S Challenger II 31722

Yamaha 9335NYSII

Getzen 3050

An "all-around" trumpet should be playable in all situations and of good quality. The Bach 18037 and Yamaha YTR-8335 are the most standard instruments in this category.

\section{Symphonic Trumpets}

Bach 18037

Edwards Generation 2

Bach 18072

Schilke S23HD

Bach AB190

Yamaha YTR-6335

Bach AB19037

Yamaha YTR-8335

B\&S Challenger II 31722

Yamaha YTR-9335CHSII

Getzen 3051

Yamaha YTR-9335NYSII 
A good symphonic Bb will have a rich, dark sound and an open blow. The Bach 18072, Yamaha 9335 trumpets, or Schilke S23HD are good trumpets for this use.

\section{$\underline{\text { Jazz/Lead }}$}

Bach 18043

Schilke B2

Bach LR19043B

Schilke B6

B\&S Challenger II 31432

Schilke S43HD

B\&S eXquisite EXB

Schilke S43HDSL-F

B\&S JBX

Schilke HC1

Getzen 3052

Schilke HC2

Getzen 3001

Yamaha YTR-8310Z

Getzen 3003 Genesis

Yamaha YTR-8335LA

Edwards Generation 3

Yamaha YTR-9340EM

Edwards Generation 3X

Instruments used for jazz and lead trumpet playing do not need to be as traditional as trumpets used in symphonic performance, thus many more models are acceptable in this category.

Generally, the trumpet should have an efficient upper register and a brighter sound. A Bach 18043 and any Yamaha or Schilke instrument listed are great choices.

\section{Trumpets}

Orchestral Trumpets

Bach C180L239

Getzen 3072

Bach C180L229W30

Edwards Generation 4

Bach C180SL229CC

Schilke S22CHD

Bach C180SL229PC

YamahaYTR-9445CHSII

Bach AC190

Yamaha YTR-9445NYSII

B\&S Challenger II 3136

Yamaha YTR-9445NYSII-YM

Getzen 3070 
For orchestral work, a very specific sound must be achieved for purposes of blend within a section. A Bach with the 229 bell is the most standard sound, but any of the Yamaha instruments listed would be an excellent, although expensive, choice.

\section{$\underline{\text { Solo/Chamber }}$}

Bach C180L239

Bach C180SL229CC

B\&S eXquisite EXC

Getzen 3071

Edwards Generation 2

Edwards Generation 3

Edwards Generation 3X
Schilke C1

Schilke C3

Schilke CX

Schilke C3HD

Yamaha YTR-8445II

Yamaha YTR-9445CHSII

A C trumpet used for solo or chamber playing should have a warm sound, and perhaps a slightly tighter blow to help with efficiency; volume is not the premium concern. Any of the Schilke instruments are ideal due to their impeccable intonation. A Bach with a 239 bell and 25C leadpipe or the Yamaha YTR-9445CHSII are also good choices. 


\section{Bibliography}

Bach Loyalist. "Bach Trumpets - Bells.” Bach Loyalist. 2006. Accessed April 5, 2017. http://www.bachloyalist.com/bach-trumpets-bells/.

Bach Loyalist. "Bach Trumpets - Bell Variations." Bach Loyalist. 2006. Accessed April 5, 2017. http://www.bachloyalist.com/bach-trumpets-bell-variations/.

Bach Loyalist. "Bach Trumpets - Leadpipes.” Bach Loyalist. 2006. Accessed April 5, 2017. http://www.bachloyalist.com/bach-trumpets-leadpipes/.

Bach Loyalist. "Bach Trumpets - Models.” Bach Loyalist. 2006. Accessed April 5, 2017. http://www.bachloyalist.com/vincent-bach-trumpet-models/.

Buffet Crampon. "B\&S Trumpets.” Buffet Crampon. 2016. Accessed April 6, 2017. http://www.b-and-s.com/en/instruments/trumpets/.

Conn-Selmer. “Conn Selmer: Professional Trumpets.” Conn-Selmer, Bach Brass. 2017. Accessed April 5, 2017. http://www.bachbrass.com/bach/instruments/trumpets/professional.

Donaldson, Jim. "Bell and Slide Options.” The Schilke Loyalist. 2006. Accessed April 8, 2017. http://www.dallasmusic.org/schilke/Bells,\%20slides\%20and\%20finish.html\#Bell\%20lab els.

Donaldson, Jim. "Schilke Bb Trumpets.” The Schilke Loyalist. 2006. Accessed April 8, 2017. http://www.dallasmusic.org/schilke/B\%20flat\%20trumpets.html.

Donaldson, Jim. "Schilke C Trumpets.” The Schilke Loyalist. 2006. Accessed April 8, 2017. http://www.dallasmusic.org/schilke/C\%20trumpets.html.

Edwards Instrument Company. "Edwards Trumpets." Edwards Instrument Company. 2017. Accessed April 7, 2017. http://www.edwards-instruments.com/trumpet/bells/index.php.

Edwards Instrument Company. "Frequently Asked Questions." Edwards Instrument Company. 2017. Accessed April 7, 2017. http://www.edwards-instruments.com/edwards/faq.php.

Edwards Instrument Company. Trumpet and Trombone Inventory Catalogue, Elkhorn, WI: Edwards Instrument Company.

Edwards Instrument Company. "Trumpet Leadpipes.” Edwards Instrument Company. 2017. Accessed April 7, 2017. http://www.edwards-instruments.com/trumpet/options/leadpipes.php.

Getzen Co. “Getzen History.” Getzen Co. 2008. Accessed April 7, 2017. http://getzen.com/inside/history.shtml. 
Getzen Co. "Getzen Trumpets.” Getzen Co. 2016. Accessed April 7, 2017. http://getzen.com/trumpet/.

Getzen Co. "Specialty Trumpets.” Getzen Co. 2016. Accessed April 7, 2017. http://getzen.com/trumpet/specialty/.

Getzen Co. "What is a Hand Hammered Bell?" Getzen Co. March 10, 2009. Accessed April 7, 2017. http://www.getzen.com/gazette/2009/03/10/what-is-a-hand-hammered-bell/.

Getzen Company, Inc.. Getzen Inventory Catalogue. Elkhorn, WI: Getzen Company, Inc.

Hempley, Roy. "Resurrection of a Chicago C or How I Came to Play Like Bud Herseth." Vincent Bach's World. 2001. Accessed April 12, 2017. http://www.vincentbachsworld.com/index_Frames.php?iframe=Other\%20Aricles\%20and $\% 20$ Tidbits/Resurrection\%20Of\%20A\%20Chicago\%20C/Resurrection\%20Of\%20A\%20 Chicago\%20C.htm.

JA Musik. The B\&S Challenger Trumpet Line Inventory Catalogue. Markneukirchen, Germany: Buffet Crampon Deutschland GmbH.

Schilke Music Products. "Our Company.” Schilke Music Products. 2014. Accessed April 8, 2017, http://www.schilkemusic.com/our-company/.

Schilke Music Products, Inc.. Trumpets \& Cornets Brochure. Melrose Park, IL: Schilke Music Products, Inc.

Vincent Bach. Bach Stradivarius Inventory Catalogue. Elkhart, IN: Conn-Selmer Inc., 2005.

Vincent Bach. The Artisan Collection: Bach Stradivarius Information Sheet. Elkhart, IN: ConnSelmer Inc.

Vincent Bach. Trumpet and Trombone Inventory Catalogue. Elkhart, IN: Conn-Selmer Inc.

Yamaha Corporation. "Trumpets - Brass/Woodwinds - Musical Instruments - Products Yamaha United States." Yamaha Corporation of America and Yamaha Corporation. 2017. Accessed April 6, 2017. http://usa.yamaha.com/products/musicalinstruments/winds/trumpets/.

Yamaha Corporation of America. Trumpets Inventory Catalogue. Buena Park, CA: Yamaha Corporation.

Yamaha Corporation of America. Wind Instruments Inventory Catalogue. Buena Park, CA: Yamaha North American Edition, 2014. 